\title{
Dificultades del Aprendizaje sobre el principio de Arquímedes en el contexto de la Flotación
}

\author{
Learning difficulties on Archimedes' Principle in the floating context
}

\author{
Lina Viviana Melo Niño*1, Ramiro Sánchez ${ }^{2}$, Florentina Cañada ${ }^{1}$, Guadalupe Martínez ${ }^{1}$ \\ ${ }^{1}$ Universidad de Extremadura, Departamento de Didáctica de las Ciencias Experimentales y las Matemáticas, \\ Badajoz, Extremadura, España \\ ${ }^{2}$ Centro de Investigaciones Científicas y Tecnológicas de Extremadura, Badajoz, Extremadura, España
}

\begin{abstract}
Recebido em 31 de março de 2016. Revisado em 30 de maio de 2016. Aceito em 15 de junho de 2016
El propósito de este artículo es describir la construcción y validación de un test de selección múltiple con una única respuesta para identificar las ideas alternativas de los estudiantes de secundaria y bachillerato sobre el empuje en el contexto de la flotación. Como referente se ha tomado la teoría clásica del test, además describimos las ideas alternativas encontradas durante el proceso de construcción de las preguntas y sus distractores. El test fue implementado a una muestra de 168 sujetos de España y Colombia con diferentes niveles educativos. Los resultados más significativos indican que los participantes de forma nemotécnica intentan recordar la postulación del principio de Arquímedes sin reparar en un análisis de fuerzas, y en identificar los dos cuerpos que interactúan y que nos permiten hablar de la fuerza de empuje. La mayoría de los sujetos participantes consideran que el empuje depende la posición del objeto sumergido.
\end{abstract}

Palabras clave: test, dificultades de aprendizaje, principio de Arquímedes.

The purpose of this article is to describe the construction and validation of a multiple choice test to identify misconceptions of middle and high school students about the Archimedes' principle in the floating context. We have taken as a reference classical theory test; also, we described, the misconceptions identified during the analysis process. The test was implemented to a sample of 168 subjects from Spain and Colombia with different educational levels. The most significant results indicate that participants try to remember the mnemonic form application of the Archimedes' principle regardless forces analysis, and participants do not identify the two bodies interact and allow us to speak of the buoyant force. They consider that buoyant force depends the position of the submerged object.

Keywords: test, learning difficulties, Archimedes' principle.

\section{Introducción}

El empuje es un concepto jerárquico que requiere relacionar conceptos como masa, volumen, densidad, y peso aparente [1]. Su aprendizaje presenta una gran dificultad para los estudiantes de todos los niveles educativos. En la enseñanza tradicional de la hidrostática el empuje cobra existencia al enunciarse el principio de Arquímedes, aunque cuando se hace referencia a este contenido, no se profundiza en las causas de esta fuerza [2]. La forma casi nemotécnica de considerar el empuje a través de la formulación

*Endereço de correspondência: lina.viviana.melo@gmail.com del principio de Arquímedes, junto con las ideas que los estudiantes mantienen sobre la fuerza como magnitud, y las representaciones de esta fuerza en las explicaciones sobre la flotación, hacen que los estudiantes utilicen el empuje como sinónimo de presión hidrostática.

El trabajo aquí presentado se estructura en cuatro partes. La primera presenta una revisión de las diferentes dificultades reportadas en la literatura sobre la comprensión que estudiantes de distintos niveles educativos realizan sobre el principio de Arquímedes en el contexto de la flotación en líquidos. La segunda parte del trabajo recoge el análisis de 7 libros de 
texto utilizados en la enseñanza en secundaria y bachillerato, tres en España y cuatro en Colombia. La tercera parte del trabajo presenta un cuestionario para la detección de ideas alternativas sobre el empuje y su validación. En el último apartado se describen algunas de las ideas alternativas encontradas en las poblaciones intervenidas. El cuestionario fue implementado a una muestra de 168 sujetos, 80 de nacionalidad española y 88 de nacionalidad colombiana, todos de diferentes niveles educativos.

\subsection{Análisis de las investigaciones sobre la enseñanza del principio de Arquímedes en el contexto de la flotación}

En términos generales, el contexto de presentación del empuje suele ser el principio de Arquímedes. Este principio de carácter empírico fue posteriormente avalado mediante las leyes de Newton donde, la fuerza de flotabilidad tiene su naturaleza en las presiones que ejerce el fluido sobre el cuerpo, cuando éste se encuentra sumergido en su interior [3, 4]. Son muchos los investigadores [2,5-10] que dan cuenta de la problemática sobre la enseñanza de la fuerza de empuje en distintos niveles educativos, y sus consecuencias en la comprensión del comportamiento de líquidos estacionarios.

La mayoría de las investigaciones se centran en estudiar las variables que los alumnos utilizan para describir el empuje (masa o peso del cuerpo, volumen, nivel de hundimiento dependiendo de la forma del objeto, densidad del fluido...), en el contexto de la flotación en líquidos. A partir de estos estudios se concluye que la descripción de la flotación en términos de las fuerzas permite explicaciones más intuitivas sobre el fenómeno de la flotación. Sin embargo, se siguen utilizando modelos galileanos vinculados con el equilibrio de densidades o pesos específicos, dejando de lado modelos que vinculan el gradiente de presiones y la energía mínima. Al respecto, Álvarez y Bernal [7] señalan como la enseñanza de la flotación se ha centrado en una versión galileana del principio de Arquímedes, en la que se incluye la comparación de densidades, que aunque nos permite predecir y cuantificar el fenómeno de la flotación en situaciones particulares, no proporciona una explicación del por qué aparece una fuerza de empuje de los cuerpos sumergidos.

Maturano et al. [11] hace mención a los distintos modelos empleados para dar cuenta del fenómeno de flotación retomando las reflexiones de Álvarez y Bernal [7]: el de Arquímedes, el de Galileo, el de densidades o peso específico, el de diferencia de presiones y el de energía mínima. Los autores relatan la utilización de algunos de estos modelos en las distintas etapas educativas y la falta de vinculación entre ellos que los profesores realizan durante sus clases.

Barral [5] indica que el concepto clave para entender la flotación es el empuje. Sin embargo muestra como el aprendizaje mecánico y memorístico del principio de Arquímedes influye en el aprendizaje significativo de este concepto, así como las dificultades derivas del aprendizaje de la noción de fuerza. Indica que además influye la perspectiva desde la cual vemos los cuerpos flotar y el uso de la preposición "sobre" en el lenguaje ordinario cuando se trata con problemas de flotación. Su estudio con 108 estudiantes de bachillerato en España, reporta que no se aprecia la necesidad de la existencia del empuje para que los objetos floten, y la idea de equilibrio hace que consideren que no actúan fuerzas sobre los objetos sumergidos.

Heron et al. [8], Loverude et al. [10], Barral [5] y Álvarez y Bernal [7] encuentran en sus investigaciones que la descripción del empuje en términos del gradiente de presiones y el peso del líquido desplazado es crucial para la comprensión de la flotabilidad. Sin embargo, Heron et al. [8] y Loverude et al. [10] en el desarrollo e implementación de distintos materiales curriculares para futuros profesores de primaria, y estudiantes de secundaria, encuentran que, muchos estudiantes no pueden aplicar el principio de Arquímedes incluso en situaciones muy sencillas. También perciben que los estudiantes de los niveles educativos estudiados, se les dificulta la operacionalización de los conceptos masa y volumen, además asocian proporcionalmente el empuje con la masa del cuerpo sumergido.

Mazzitelli et al. [12] analizan las dificultades conceptuales sobre la formulación matemática del principio de Arquímedes y su relación con la explicación física del fenómeno de flotación con 25 profesores y 64 estudiantes de secundaria, encuentra que ambas poblaciones: a) no reconocen los factores que afectan el empuje; b) en las situaciones donde estudiantes y/o profesores recuerdan la fórmula respectiva, no están en condiciones de aplicarla en la predicción de fenómenos relevantes; c) no se aprecia la necesidad de la existencia del empuje para que los objetos floten; d) el volumen en la mayoría de los casos no 
forma parte de los conceptos con los que construyen sus teorías sobre la flotación; e) sólo los sujetos de mayor edad relacionan el peso y el volumen del objeto; f) el peso se considera un factor esencial en la explicación del fenómeno de la flotación; y g) la profundidad es un factor a considerar en la flotabilidad.

Alurralde y Salinas [13] aplicaron cuatro cuestionarios a 383 estudiantes universitarios y realizaron entrevistas semiestructuradas sobre cuestiones experimentales relacionadas con el empuje. Los resultados reportan cuatro modelos alternativos utilizados por los estudiantes: a) las variables relevantes con relación al empuje son variables vinculadas sólo al cuerpo que se sumerge (peso/masa, densidad, volumen); b) las variables relevantes con relación al empuje, son variables vinculadas sólo al líquido (presión, profundidad); y, c) el empuje es mayor cuando el cuerpo está a menor profundidad (grados de flotabilidad). La respuesta más recurrente por los estudiantes suele asociar la posición relativa de los cuerpos completamente sumergidos en el líquido con un grado de flotabilidad, es decir los estudiantes consideran que los cuerpos totalmente sumergidos flotan más cuando se encuentra a un nivel más alto del líquido que cuando se encuentra en un nivel más bajo. Los autores atribuyen estas explicaciones a las representaciones utilizadas para dar cuenta de las condiciones de flotación.

Echegaray et al. [14] analizando el lenguaje escrito de un grupo de estudiantes de secundaria sobre la noción de presión, encuentran que los estudiantes relacionan la presión hidrostática con un empuje o fuerza hacia arriba que realiza el agua sobre los sólidos sumergidos. Utilizan una visión animista donde el agua tiende a elevar los cuerpos. En algunos casos no mencionan específicamente la idea de fuerza, pero recurren a diversos términos que dan cuenta de una "fuerza" dirigida hacia arriba que hace "subir" el cuerpo.

García-Carmona [15] plantea una propuesta de enseñanza para abordar los contenidos de hidrostática con estudiantes de secundaria a través de un modelo de aprendizaje por investigación. La propuesta se evalúa a través de las actitudes de los estudiantes hacia el aprendizaje de la hidrostática y los niveles de comprensión adquiridos por los estudiantes. El papel del proceso de autorregulación practicado durante la realización de las actividades fue uno de los elementos facilitadores en el aprendizaje de los estudiantes. Las dificultades que permanecen o aparecen después de la instrucción relacionadas con el empuje fueron: a) el empuje sobre un cuerpo totalmente sumergido en un líquido depende de la profundidad a la que éste se encuentre, b) los líquidos "amortiguan" el hundimiento de los cuerpos como si fuesen un "soporte elástico", y no porque ejercen una fuerza neta vertical y hacia arriba.

Madrigal y Slisko [16], relatan las dificultades y explicaciones dadas por estudiantes mexicanos de bachillerato sobre el por qué un frasco flota en el agua y se hunde en el aceite. Los marcos interpretativos utilizados por los estudiantes son por lo general monocausales relacionados con el peso de los objetos $\mathrm{u}$ otra propiedad del cuerpo que se sumerge. Otros marcos interpretativos que emplean los estudiantes para los fenómenos de flotación y hundimiento son: a) uniformidad de los tamaños y pesos moleculares de diferentes sustancias; b) la direccionalidad de la presión; c) las fuerzas externas, como gravedad, que afectan la presión; d) la presión afecta la densidad; y e) el área afecta la acción de las fuerzas externas sobre la presión. La utilización del modelo científico policausal donde la flotación de los cuerpos se debe a la relación de las intensidades de dos fuerzas de sentidos opuestos se utiliza en escasa proporción y sólo cuando se les proporciona a los estudiantes situaciones complejas.

Finalmente, Buteler y Colenu [2] caracterizan las respuestas de dos estudiantes universitarios de segundo año de licenciatura en física en Argentina, una vez finalizan su física II donde se vinculan contenidos de hidrostática. Los investigadores concluyen que el contexto del problema es un condicionante para su solución. Indican que los estudiantes tienen mayor dificultad en aquellos problemas que requieren las causas de la fuerza del empuje y su relación con la presión hidrostática.

A lo largo de la revisión encontramos cinco categorías frecuentes en la descripción de las dificultades de aprendizaje que los estudiantes de los distintos niveles educativos mantienen sobre el empuje: a) la fuerza de empuje depende de las características o propiedades del cuerpo que se sumerge (peso, masa, densidad, volumen, área); b) la fuerza de empuje se relaciona sólo con el líquido donde se sumergen los cuerpos (presión y profundidad); c) no se considera la existencia del empuje; d) las ideas heredadas sobre la fuerza influyen en la representación del empuje; e) se desconoce las causas del empuje. Un 
resumen de esta revisión según las categorías expuestas se encuentra en la tabla 1 donde se han recopilado las ideas alternativas utilizadas por los estudiantes alrededor del principio de Arquímedes. Las soluciones a estas dificultades se basan en una estructura conceptual donde prima la idea de presión sin hacer mención a su definición en términos de fuerza como concepto articulador en la enseñanza de la hidrostática, y definir el empuje en términos de la diferencia de presiones haciendo énfasis en la interacción fluido-sólido.

\subsection{Tratamiento dado al principio de Arquímedes en los libros de texto e ideas alternativas promovidas.}

Los libros de texto son uno de los recursos más utilizados en las clases de ciencias, tienen una influencia notable en las acciones que se desarrollan en el aula [9, 23]. Dado el gran efecto de este material curricular en el aprendizaje y la enseñanza, presentamos a continuación el resultado de la revisión realizada de algunos libros de texto utilizados en la enseñanza de la física y química en España (E) y Colombia (C) alrededor de la fuerza de empuje

Tabla 1: Ideas alternativas utilizadas por los estudiantes sobre el principio de Arquímedes

\begin{tabular}{|c|c|}
\hline Categoría & Dificultad de Aprendizaje \\
\hline \multirow{6}{*}{$\begin{array}{l}\text { La fuerza de empuje depende } \\
\text { de las características o } \\
\text { propiedades del cuerpo que se } \\
\text { sumerge (peso, masa, densidad, } \\
\text { volumen, área, empuje) }\end{array}$} & $\begin{array}{l}\text {-El volumen del líquido desplazado por un cuerpo sumergido depende de la forma, la } \\
\text { masa o la densidad del sólido, y no de su volumen }[10,12,15,17]\end{array}$ \\
\hline & - El peso de un cuerpo determina el empuje que hace el líquido sobre éste $[10,12,15,17,18]$ \\
\hline & $\begin{array}{l}\text {-El empuje sobre un cuerpo totalmente sumergido en un líquido depende de la profundidad } \\
\text { a la que éste se encuentre, grados de flotabilidad }[10,13,15,19]\end{array}$ \\
\hline & $\begin{array}{l}\text {-No hay relación consistente entre masa, volumen, densidad y gravedad y la fuerza de } \\
\text { empuje[10] }\end{array}$ \\
\hline & $\begin{array}{l}\text { - No se tiene en cuenta la incompresibilidad o la densidad del líquido en el cual se } \\
\text { sumergen los cuerpos para dar cuenta de la flotabilidad [10] }\end{array}$ \\
\hline & $\begin{array}{l}\text {-El empuje depende del tamaño del área sumergida es una propiedad de los cuerpos } \\
{[19,20,21,22]}\end{array}$ \\
\hline \multirow{3}{*}{\begin{tabular}{l|} 
La fuerza de empuje se \\
relacionan sólo al líquido \\
donde se sumergen los cuerpos \\
(presión, profundidad...)
\end{tabular}} & -El empuje depende de la densidad del líquido en el que se sumerge el cuerpo [13] \\
\hline & $\begin{array}{l}\text {-El empuje depende de la cantidad (volumen) de líquido contenida en el recipiente en el } \\
\text { que se sumerge el cuerpo, o que dicho cuerpo tiene encima }[2,12,13]\end{array}$ \\
\hline & $\begin{array}{l}\text { - Un cuerpo sumergido en un líquido modifica algunas propiedades físicas de este último, } \\
\text { como la densidad [15] }\end{array}$ \\
\hline \multirow[t]{5}{*}{$\begin{array}{l}\text { Ideas heredadas sobre la fuerza } \\
\text { influyen en la representación } \\
\text { del empuje }\end{array}$} & $\begin{array}{l}\text { - Los líquidos "amortiguan" el hundimiento de los cuerpos como si fuesen un "soporte } \\
\text { elástico", y no porque ejercen una fuerza neta vertical y hacia arriba (empuje), esta es } \\
\text { la causa de la disminución de peso del cuerpo sumergido [15] }\end{array}$ \\
\hline & $\begin{array}{l}\text { El único factor causal para la flotación o el hundimiento es el peso del objeto } \\
{[5,11,16,17,18]}\end{array}$ \\
\hline & $\begin{array}{l}\text {-La flotación se explica sólo como causa de la diferencia de densidades, en ocasiones se } \\
\text { asume que los cuerpos sumergidos en un liquido modifican algunas de sus propiedades } \\
\text { físicas, como su densidad o volumen }[12,15]\end{array}$ \\
\hline & $\begin{array}{l}\text {-Las razones dadas para la flotación de los cuerpos se basan en la longitud, el material, } \\
\text { la forma, la presencia de los huecos o el aire dentro del objeto, la manera de colocar el } \\
\text { objeto en el agua, etc. }[12,16,17]\end{array}$ \\
\hline & $\begin{array}{l}\text {-El concepto de flotación necesita ser ampliado para comprender o vincular el empuje y } \\
\text { la densidad [17] }\end{array}$ \\
\hline \multirow[t]{3}{*}{$\begin{array}{l}\text { Representación de las Fuerzas } \\
\text { dificulta la representación del } \\
\text { Empuje }\end{array}$} & $\begin{array}{l}\text {-Representan las fuerzas vinculadas al cuerpo que se sumerge en cualquier lugar del } \\
\text { esquema sin considerar el punto de aplicación de las mismas, es decir no se considera el } \\
\text { centro de empuje [12] }\end{array}$ \\
\hline & $\begin{array}{l}\text {-Dificultad en determinar la localización, dirección, magnitud y sentido del empuje y su } \\
\text { par sobre el fluido [2] }\end{array}$ \\
\hline & $\begin{array}{l}\text {-Indican que el vector peso y el vector empuje son iguales, sin considerar sus sentidos } \\
{[12]}\end{array}$ \\
\hline \multirow{4}{*}{$\begin{array}{l}\text { Se desconoce las causas del } \\
\text { empuje }\end{array}$} & -Presión y Empuje como sinónimos [14] \\
\hline & -Se conjuga el principio de Arquímedes y Pascal para dar cuenta del empuje $[2,12,22]$ \\
\hline & $\begin{array}{l}\text { - No se concibe el empuje como resultado de un balance de presiones hidrostáticas, con } \\
\text { sentidos opuestos, en la dirección vertical [15] }\end{array}$ \\
\hline & - El empuje es inexistente cuando los objetos estár \\
\hline
\end{tabular}


tanto en secundaria como en bachillerato. Estos libros de texto han sido utilizados por la mayoría de los participantes de nuestra muestra de estudio. Los libros de texto destinados a la enseñanza secundaria están dirigidos a estudiantes entre 14 y 16 años y los de bachillerato entre 16 y 18 años. El objetivo de este análisis es determinar si "el tratamiento dado a la fuerza de empuje puede contribuir a generar o reforzar ideas alternativas en el alumnado, o por el contrario favorece la evolución conceptual hacia ideas científicamente aceptadas" [24, p. 300]. Los libros de texto seleccionados y sus características son resumidos en la tabla 2 .
En la figura 1 se muestra un mapa conceptual sobre la secuencia de los contenidos de los libros de texto analizados. La estructura de los libros de texto E1 y E2, muestran una separación entre la flotación y el concepto de presión, el resto de libros de texto integran las causas del empuje en términos de gradientes de fuerzas (E2) o de presiones (C1, $\mathrm{C} 2, \mathrm{C} 3$ y C4).

La secuencia de contenidos inicia caracterizando los fluidos y realizando distinciones entre líquidos y gases, resaltando el papel de la densidad como propiedad distintiva, a continuación se describe el concepto de presión en términos de la relación fuerza sobre área y posteriormente se define la presión en

Tabla 2: Libros de texto utilizados en la investigación

\begin{tabular}{|c|c|c|c|c|c|c|}
\hline & Código & $\begin{array}{l}\text { Editorial } \\
\text { (Año de } \mathrm{Pu}- \\
\text { blicación) }\end{array}$ & Curso & Autores & $\begin{array}{l}\mathrm{N}^{\circ} \text { de Apar- } \\
\text { tados }\end{array}$ & $\begin{array}{l}\mathrm{N}^{\circ} \text { páginas/\% } \\
\text { del Libro }\end{array}$ \\
\hline \multirow{6}{*}{ España } & \multirow[t]{2}{*}{ E1 [25] } & \multirow{2}{*}{$\begin{array}{l}\text { Everest } \\
(2003)\end{array}$} & \multirow[t]{2}{*}{$4^{\circ} \mathrm{ESO}^{*}$} & \multirow{2}{*}{$\begin{array}{l}\text { Fidalgo, J.A y Fernández } \\
\text { M.R. }\end{array}$} & \multirow[t]{2}{*}{8} & 19 \\
\hline & & & & & & $9.5 \%$ \\
\hline & \multirow[t]{2}{*}{ E2 [26] } & \multirow[t]{2}{*}{$\begin{array}{l}\text { Bruno } \\
(2007)\end{array}$} & \multirow[t]{2}{*}{$4^{\circ} \mathrm{ESO}$} & \multirow{2}{*}{$\begin{array}{l}\text { Ontañón, G; Ontañon, E; } \\
\text { Fernández-Cano, J.A; Arce, } \\
\text { F. }\end{array}$} & \multirow[t]{2}{*}{7} & 21 \\
\hline & & & & & & $9.4 \%$ \\
\hline & \multirow{2}{*}{ E3 [27] } & \multirow{2}{*}{$\begin{array}{l}\text { Vicens } \\
\text { Vives (2008) }\end{array}$} & \multirow[t]{2}{*}{$4^{\circ} \mathrm{ESO}$} & \multirow{2}{*}{$\begin{array}{l}\text { Fontanet, A y Martínez, } \\
\text { M.J. }\end{array}$} & \multirow[t]{2}{*}{6} & 21 \\
\hline & & & & & & $7.7 \%$ \\
\hline \multirow{8}{*}{ Colombia } & \multirow[t]{2}{*}{ C1 [28] } & \multirow{2}{*}{$\begin{array}{l}\text { Pearson } \\
(2007)\end{array}$} & \multirow[t]{2}{*}{ Secundaria } & \multirow[t]{2}{*}{ Hewitt, $\mathrm{P}$. } & \multirow[t]{2}{*}{22} & 59 \\
\hline & & & & & & $7.2 \%$ \\
\hline & \multirow[t]{2}{*}{$\mathrm{C} 2[29]$} & \multirow{2}{*}{$\begin{array}{l}\text { Santillana } \\
(2011)\end{array}$} & \multirow{2}{*}{$\begin{array}{l}\text { Secundaria/ } \\
\text { Bachillerato }\end{array}$} & \multirow[t]{2}{*}{ Romero, O y Bautista, M } & \multirow[t]{2}{*}{11} & 26 \\
\hline & & & & & & $7.5 \%$ \\
\hline & \multirow[t]{2}{*}{ C3 [30] } & \multirow{2}{*}{$\begin{array}{l}\text { Pearson } \\
(2008)\end{array}$} & \multirow[t]{2}{*}{ Bachillerato } & \multirow[t]{2}{*}{ Giancoli, D. } & \multirow[t]{2}{*}{13} & 31 \\
\hline & & & & & & $3.4 \%$ \\
\hline & \multirow[t]{2}{*}{$\mathrm{C} 4[31]$} & \multirow{2}{*}{$\begin{array}{l}\text { McGraw } \\
\text { Hill (2011) }\end{array}$} & \multirow[t]{2}{*}{ Bachillerato } & \multirow[t]{2}{*}{ Tippens, $\mathrm{P}$} & \multirow[t]{2}{*}{11} & 27 \\
\hline & & & & & & $3.5 \%$ \\
\hline
\end{tabular}

*ESO: Educación Secundaria Obligatoria

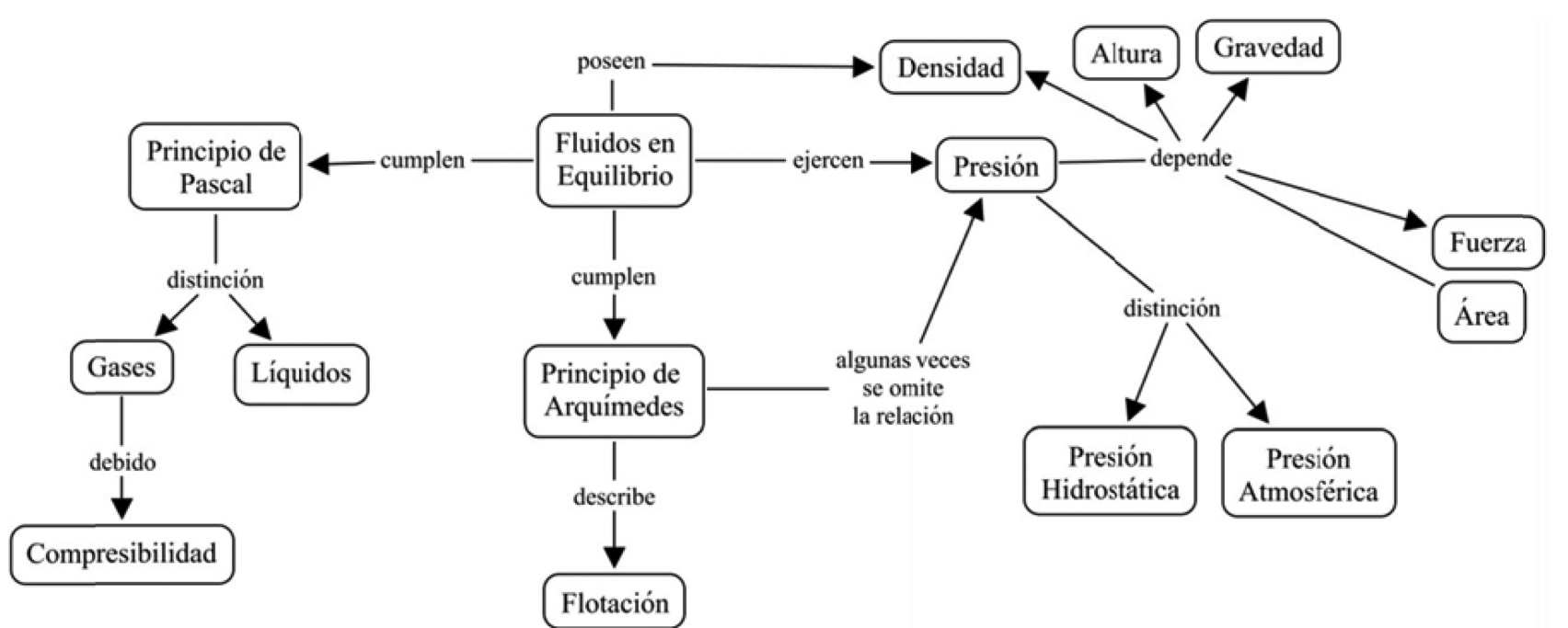

Figura 1: Mapa Conceptual sobre las tendencias en la presentación secuencial de los contenidos en los libros de texto analizados 
líquidos y gases. Se finaliza con la descripción del principio de Pascal y Arquímedes. De forma genérica en todos los libros suele presentarse primero la definición de presión en términos de fuerza (presión en los sólidos) y luego se vincula la relación entre gravedad, profundidad, altura y, densidad. Aunque la mayoría de los textos indican la diferencia entre presión y fuerza no siempre se explicita.

A partir del patrón temático, que muestran los libros de texto, tres contenidos resultan comunes: i) fluidos, definición y propiedades; ii) presión que ejercen los fluidos, y iii) Principios o teoremas relacionados con los fluidos. A través de la tabla 3, resumimos la idea central relacionada con cada contenido y a su vez los hechos, y conceptos vinculados. El empuje aparece ligado a la presentación del principio de Arquímedes, el cual es descrito luego de definir el principio de Pascal (a diferencia del libro C1) y sus aplicaciones. Sólo el libro E2 presenta interrelación entre los dos principios describiendo el comportamiento del "diablito de Descartes".

El contexto de introducción de la fuerza de empuje en todos los libros de texto es el peso aparente. El empuje se introduce para explicar el hecho experiencial que relata la "aparente pérdida de peso" cuando se sumergen en agua los sólidos. E1 y C3 utilizan el problema de la corona de Arquímedes para ambientar la introducción del contenido. Slisko [32, 33] indica que la formulación del problema de la corona de Arquímedes en los términos del peso aparente se encuentra lejos de la solución que Arquímedes pudo dar en su tiempo. Sólo C3 da soporte gráfico a la solución de la corona de Arquímedes.

Como mostramos en la tabla 4, son múltiples los enunciados utilizados para dar cuenta del principio de Arquímedes. E1 y C2 aclaran que el principio caracterizará los sólidos sumergidos en líquidos. E1, E3 y C4 indican que el principio da cuenda de todos los cuerpos que están sumergidos total o parcialmente en un fluido, mientras que E2, C1, C2 y C3 lo postulan sólo para los cuerpos sumergidos en el fluido. A excepción de C3 todos afirman que el empuje es una fuerza hacia arriba; E1, E2 y C2 aclaran que es vertical, reforzando la dirección y sentido del empuje. E1, E2, C1, C3 y, C4 señalan que la magnitud del empuje es igual a la magnitud del peso del líquido desalojado, E3, C2 insisten en indicar que la magnitud es igual al volumen del líquido desalojado. E1 y E2 no aclaran lo que significa "desalojado". Desalojado es un término técnico que puede resultar evidente para quien conoce bien el principio de Arquímedes, pero no lo es para quien se lo encuentra por primera vez.

A diferencia de E1, los libros E2, E3, C1, C3 y $\mathrm{C} 4$ presentan el empuje como una consecuencia de las diferencias de presión (o fuerza debido a la di-

Tabla 3: Contenidos e Ideas Centrales presentes en los libros de texto analizados

\begin{tabular}{|c|c|c|}
\hline \multicolumn{3}{|c|}{ Contenidos e Ideas Centrales } \\
\hline Cont. & Ideas Centrales & Conceptos, Principios y Hechos \\
\hline \multirow[t]{2}{*}{ Qué es un fluido } & Idea I: Definición & $\begin{array}{l}\text { Fases de la materia, diferencia entre líquido y gas, modelo } \\
\text { mecánico de líquido y gas, propiedades que diferencian los } \\
\text { fluidos }\end{array}$ \\
\hline & $\begin{array}{l}\text { Idea II: Densidad como propie- } \\
\text { dad de los fluidos }\end{array}$ & $\begin{array}{l}\text { Densidad relativa, densidad en los gases, densímetro, gravedad } \\
\text { específica }\end{array}$ \\
\hline \multirow[t]{3}{*}{$\begin{array}{l}\text { Presión que } \\
\text { ejercen los fluidos }\end{array}$} & $\begin{array}{l}\text { Idea I: Definición en términos de } \\
\text { fuerza y área }\end{array}$ & $\begin{array}{l}\text { Definición de presión en los sólidos, unidades de medida, ex- } \\
\text { plicación de algunos efectos de la fuerza, importancia de la } \\
\text { superficie de apoyo }\end{array}$ \\
\hline & Idea II: Presión Hidrostática & $\begin{array}{l}\text { Definición, variables que influyen en la variación de la presión } \\
\text { hidrostática (principio fundamental de la hidrostática), efectos } \\
\text { de la presión hidrostática, vasos comunicantes, paradoja de } \\
\text { Stevin }\end{array}$ \\
\hline & Idea II: Presión Atmosférica & $\begin{array}{l}\text { Definición, presión manométrica, , variables que influyen en } \\
\text { la variación de la presión hidrostática, experimento de Torri- } \\
\text { celli, manómetro, barómetro, altímetro, Ley de Boyle-Mariot, } \\
\text { meteorología, atmósfera }\end{array}$ \\
\hline \multirow{2}{*}{$\begin{array}{l}\text { Principios funda- } \\
\text { mentales }\end{array}$} & Idea I: Principio de Pascal & Enunciado del principio, aplicaciones del principio de Pascal \\
\hline & Idea II: Principio de Arquímedes & $\begin{array}{l}\text { Enunciado del principio, empuje, condiciones de flotación, peso } \\
\text { aparente, aerostación, se plantea el problema de la corona de } \\
\text { Hieron, hidrómetro }\end{array}$ \\
\hline
\end{tabular}


Tabla 4: Enunciados del principio de Arquímedes en los libros analizados

\begin{tabular}{|l|l|}
\hline E1 & $\begin{array}{l}\text { "Todo sólido sumergido total o parcialmente en un líquido (y también en un gas) experimenta un empuje } \\
\text { vertical hacia arriba igual al peso del líquido (o de gas) que desaloja" [25, p. 54] }\end{array}$ \\
\hline E2 & $\begin{array}{l}\text { "Todo cuerpo sumergido en un fluido experimenta un empuje vertical y hacia arriba igual al peso } \\
\text { del fluido desalojado" [26, p. 148] }\end{array}$ \\
\hline E3 & $\begin{array}{l}\text { "Todo cuerpo sumergido total o parcialmente en un fluido experimenta un empuje hacia arriba igual } \\
\text { al peso del volumen del líquido desalojado" [27, p. 106] }\end{array}$ \\
\hline C1 & $\begin{array}{l}\text { "Un cuerpo sumergido en un fluido sufre un empuje hacia arriba por una fuerza igual al peso del } \\
\text { fluido que desplaza" [28. p. 253] }\end{array}$ \\
\hline C2 & $\begin{array}{l}\text { "Todo cuerpo sumergido en un líquido experimenta un empuje vertical, hacia arriba, igual al peso } \\
\text { del volumen del liquido desplazado" [29, p. 191] }\end{array}$ \\
\hline C3 & $\begin{array}{l}\text { "La fuerza boyante sobre un objeto inmerso en un fluido es igual al peso del fluido desplazado por } \\
\text { el objeto" [30, p. 263] }\end{array}$ \\
\hline C4 & $\begin{array}{l}\text { "Un objeto que se encuentra parcial o totalmente sumergido en un fluido experimenta una fuerza as- } \\
\text { cendente (empuje) igual al peso del fluido desalojado" [31, p. 311] }\end{array}$ \\
\hline
\end{tabular}

ferencia de presión) en el seno de un fluido. Esto puede ayudar a restar arbitrariedad aparente a este contenido que, por otra parte, muchos alumnos asocian a la simple presencia del fluido, más que a las fuerzas de empuje que éste ejerce [23]. Sin embargo las presentaciones utilizadas en los libros E3, C1, suelen incurrir en presentar fuerza y presión como magnitudes homólogas. C1, y C2, utilizan para dar cuenta del empuje, la fuerza debida al peso del volumen del fluido sobre las caras del cuerpo sumergido, sin hacer alusión a la idea de presión.

Otras situaciones conflictivas que presentan los libros de texto analizados se suman a las reportadas por Campanario [9], Alcocer et al. [23] y Maturano et al. [34]:

i) Las situaciones que simulan el peso igual al empuje, refuerzan la idea según la cual una situación de igualdad de fuerzas debe dar lugar a una situación simétrica, debido a que los objetos sumergidos son localizados justamente a una profundidad media, a igual distancia de la superficie del líquido y del fondo como se muestra en la figura 2 (E1, E2, E3, C1, C2 y $\mathrm{C} 4)$;

ii) No se discuten las posibles excepciones del principio de Arquímedes, cuando por ejemplo un cuerpo sólido y simétrico se sumerge en un líquido, y se pone en contacto con el fondo del recipiente que contiene el fluido, como muestra E2 en el objeto c de la figura 2C. Hay evidencia empírica que sugiere que la magnitud de la fuerza de empuje incrementa linealmente con la profundidad, y su dirección va hacia abajo $[3,35]$; iii) Se salta de una fórmula expresada con fuerzas (peso $>$ Empuje) a otra expresada con densidades $\left(\right.$ densidad $_{\text {objeto }}>$ densidad $\left._{\text {agua }}\right)$, para dar cuenta de la flotación (E2), en C1 la flotabilidad se da en términos de la densidad y en el resto de libros sólo en términos de las fuerzas. En C2 no se enuncian las condiciones de flotabilidad;

iv) Se utilizan diferentes criterios (longitud o grosor de las flechas) para la representación de las fuerzas peso y empuje (E1, E3);

v) Se utilizan objetos en equilibrio en los líquidos pero cuyas fuerzas pintadas no dan resultante cero como se evidencia en la figura 3 (E1, E2);

vi) Se introduce la flotabilidad como pérdida de peso aparente $(\mathrm{C} 1)$

vii) Se introduce el peso aparente para definir el empuje asumiendo que el peso de los cuerpos sumergidos es mayor que el empuje (E1, E2, $\mathrm{E} 3, \mathrm{C} 1, \mathrm{C} 2, \mathrm{C} 3$ y C4);

viii) Se asume que a mayor volumen mayor empuje (E1).

La utilización de la idea de peso aparente y peso del volumen desalojado así como la representación de las fuerzas que experimenta un cuerpo sumergido, resultan ser los elementos más conflictivos en los libros de texto analizados, que contribuyen a la posterior memorización por parte de los estudiantes.

\section{Metodología}

En este apartado se hace una descripción del objetivo de la investigación, los sujetos que han intervenido, el diseño del test para la detección de las dificultades de aprendizaje sobre el principio 
a) Tomado de Giancoli [30, p. 264]

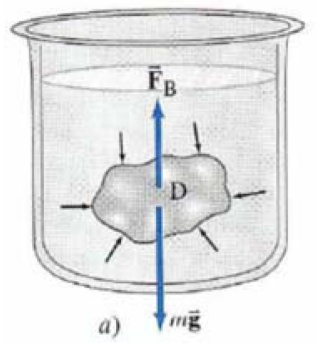

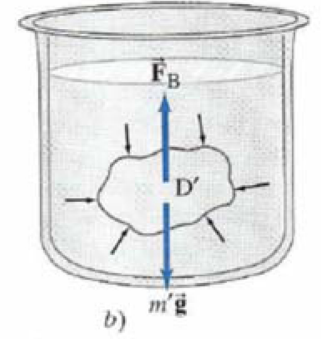

b) Tomado de Tippens [31, p. 312]

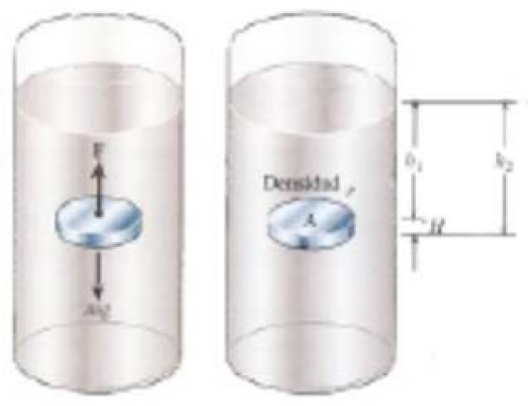

c) Tomado de Fontanet y Martínez [27, p. 106]

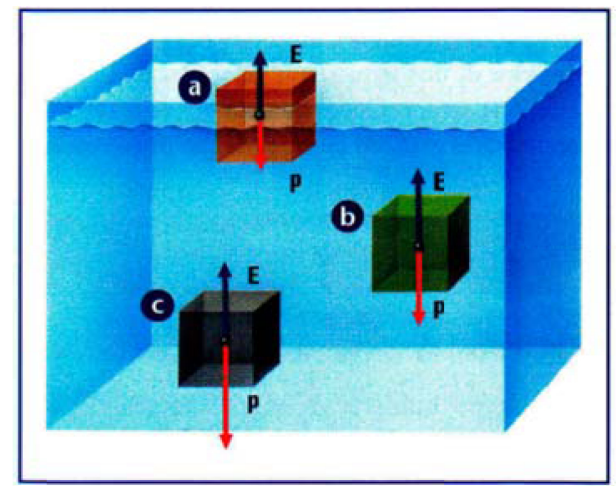

Figura 2: Representación del Equilibrio de Fuerzas de un sólido en un líquido para los libros analizados a), b), c).

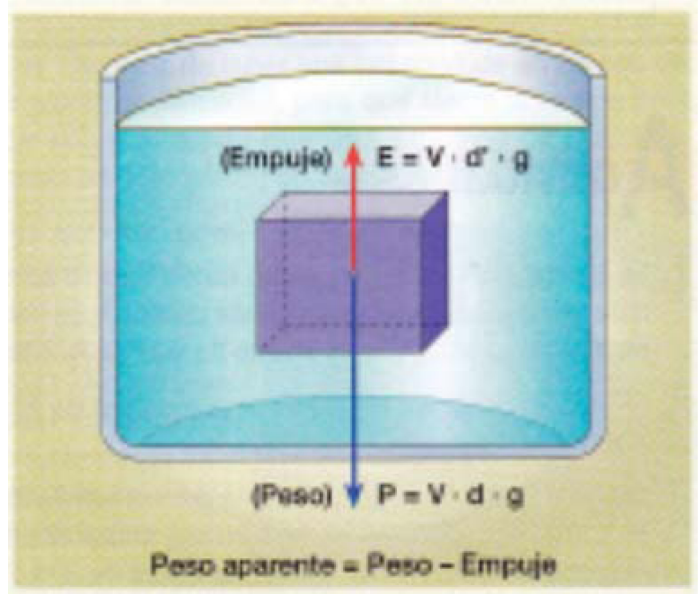

Figura 3: Representación Fuerzas que experimenta un sólido en un líquido, tomado de Fidalgo y Fernández [25, p. 54]

de Arquímedes y la determinación de la validez de contenido del test.

\subsection{Objetivo}

A partir de la conjugación de los análisis realizados desde la literatura y los libros de texto, se diseñó un test de 10 ítems para la detección de algunas dificultades frente al principio de Arquímedes que hemos denotado como TPA. El test está compuesto por ítems que "plantean una serie de situaciones para provocar en los participantes un razonamiento registrable mediante respuestas posibles de suceder como fenómeno ante la situación planteada que están en consonancia con su compresión" [36, p. 28].

\subsection{Diseño del test}

Los ítems contienen cuatro respuestas posibles cada uno, con el que se pretende detectar las siguientes ideas: Ítem 1 y 7: es posible determinar la localización, dirección, magnitud y sentido del empuje y su par sobre el fluido; Ítem 2: la fuerza de empuje depende de las características o propiedades del cuerpo que se sumerge o está en contacto con el agua; Ítem 3: a mayor peso mayor volumen de líquido desplazado, la relación presión altura es inexistente; Ítem 4: el empuje depende del volumen del cuerpo sumergido; Ítem 5 y 6: el empuje sobre un cuerpo totalmente sumergido en un líquido depende de la profundidad a la que éste se encuentre "grados de flotabilidad"; 
Ítem 8 y 9: no se concibe el empuje como resultado de un balance de presiones hidrostáticas, con sentidos opuestos, en la dirección vertical; Ítem 10: se considera el empuje y la presión como sinónimos. Además cada ítem contiene un apartado donde se solicitaba valorar el grado de seguridad en la respuesta: Totalmente Segura/o; Segura/o; Indecisa/o; $\mathrm{Al}$ azar. Dicho test se encuentra disponible en el anexo 1.

Para el diseño del test con opciones múltiples se tomaron en cuenta seis recomendaciones generales: a) los ítems diseñados cuentan con una sola respuesta correcta y tres incorrectas llamadas distractores; b) se seleccionó entre los tres distractores el llamado "mejor distractor" o la respuesta incorrecta más esperada por la población; c) los distractores han sido recopilados de los resultados de las respuestas abiertas analizadas en la literatura y la información de los libros de texto; d) se redactó un primer test borrador. Se entregó a cinco investigadores en didáctica de las ciencias para su validación; e) finalmente se redacta el primer test sobre el principio de Arquímedes (TPA) y se presenta a través de la plataforma de Google Drive- Google Form (http://goo.gl/forms/UGo7OHpUwF); f) se evalúa la confiabilidad y el poder discriminatorio del test y se establece un proceso estadístico.

\subsection{Prueba piloto}

Para poner a punto el test se aplicó a una muestra 168 sujetos de distintas edades, grado de escolaridad y edad. Nuestra intención al seleccionar una muestra de estas características se fundamentó en la permanencia de ideas alternativas, independientemente de la nacionalidad, edad, grado de escolaridad o sexo. En la tabla 5 presentamos la relación de los encuestados. La información se capturó con el formato electrónico de Google Form y se trasladó posteriormente al SPSS 19 para el análisis estadístico.

Para mostrar que el test es un instrumento de evaluación confiable y con poder discriminatorio adecuado se siguió el análisis recomendado por Ding et al. [37]. En este análisis se realizan cinco pruebas estadísticas: tres pruebas se enfocan en el análisis individual de los ítems del test (índice de dificultad del ítem, índice de discriminación del ítem y coeficiente de punto biserial del ítem) y dos pruebas en el análisis de todo el test (confiabilidad del test y delta de Ferguson). Autores como Ding et al. [37], Barbosa [36] entre muchos otros señalan que si el test cumple con estas cinco pruebas se puede concluir que el test es confiable con un poder discriminatorio satisfactorio.

\subsection{Valores de calibración del test}

A continuación describiremos los resultados de las cinco pruebas estadísticas planteadas. Los histogramas que dan cuenta de los resultados se presentan en la figura 4.

Índice de dificultad indica el grado de dificultad de un ítem dentro del test y lo denotamos con P. Se calcula dividiendo el cociente entre el número de respuestas correctas de un ítem (N1), sobre el número de sujetos que han realizado el test $(\mathrm{N})$. El

Tabla 5: Datos generales de la muestra seleccionada

\begin{tabular}{|l|l|l|l|}
\hline \multirow{4}{*}{ Sexo } & Voriable & Frecuencia & Porcentaje \\
\cline { 2 - 4 } & Mujer & 50 & $29,8 \%$ \\
\hline Nacionalidad & España & 118 & $70,2 \%$ \\
\cline { 2 - 4 } & Colombia & 80 & $47,6 \%$ \\
\hline \multirow{4}{*}{ Edad } & $\mathbf{1 5 - 1 8}$ & 88 & $52,4 \%$ \\
\cline { 2 - 4 } & $19-30$ & 66 & $39,3 \%$ \\
\cline { 2 - 4 } & $>\mathbf{3 1}$ & 26 & $15,5 \%$ \\
\hline \multirow{5}{*}{ Nivel de Escolaridad } & Secundaria & 76 & $45,2 \%$ \\
\cline { 2 - 4 } & Bachillerato & 8 & $4,8 \%$ \\
\cline { 2 - 4 } & Técnico-Tecnólogo & 76 & 45,2 \\
\cline { 2 - 4 } & Grado-Licenciatura & 16 & $9,5 \%$ \\
\cline { 2 - 4 } & Máster-Doctorado & 18 & $10,7 \%$ \\
\hline \multirow{5}{*}{ Especialidad de los Estudios } & Ciencias de la Naturaleza & 60 & $29,8 \%$ \\
\cline { 2 - 4 } & Ciencias de la Salud & 8 & $39,3 \%$ \\
\cline { 2 - 4 } & CC Sociales y Jurídicas & 4 & $4,8 \%$ \\
\cline { 2 - 4 } & Ingeniería & 26 & $2,4 \%$ \\
\cline { 2 - 4 } & Otras & 64 & $38,1 \%$ \\
\hline
\end{tabular}



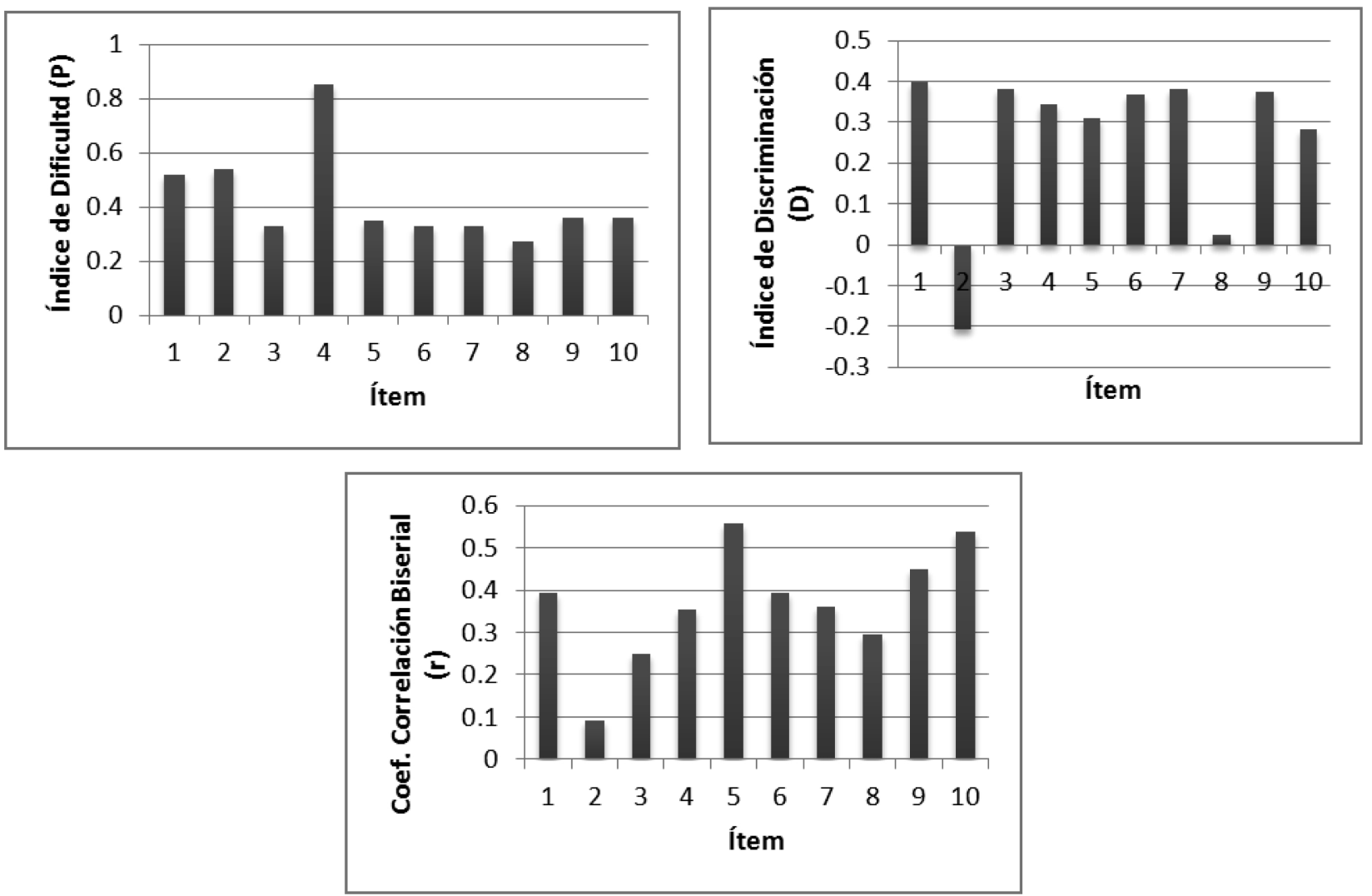

Figura 4: Índices de Calibración del TPA en una muestra de 168 sujetos

rango recomendado para este índice es entre $0.3 \mathrm{y}$ 0.9 . Se recomienda además de este indicador calcular el índice de dificultad promedio del test que es la suma de todos los índices divididos por la cantidad de ítems del test. El rango recomendado también es $(0.3,0.9)$ [36-38]. Como se evidencia en la figura 4 , el ítem 8 tienen un índice de dificultad inferior a lo deseado (0.3), lo cual nos sugiere su modificación, ya que con dificultad se puede responder correctamente a esta pregunta, de igual forma el ítem 4 aunque se encuentre dentro del rango deseable, sugiere que su respuesta es evidente. El índice de dificultad promedio del test es 0,42 lo cual sugiere que el test en su conjunto presenta una dificultad conceptual adecuada para la nuestra investigación.

Índice de discriminación el cual denotamos con $\mathrm{D}$, mide el poder discriminatorio de cada ítem en un test. Es decir permite concluir si el test puede distinguir aquellos sujetos con un conocimiento más sólido, que responden correctamente, de aquellos sujetos cuya comprensión es más débil, y mayoritariamente no seleccionan la respuesta que se ha previsto como correcta. La forma de calcular el índice es a través de $\mathrm{D}=(\mathrm{NH}-\mathrm{NL}) /(\mathrm{N} / 2)$, donde $(\mathrm{NH})$ representa la cantidad de sujetos con una calificación mayor a la mediana y (NL) la cantidad de sujetos que tienen una calificación menor a la mediana. Una buena discriminación se cumple si el resultado del índice es $\geqslant 0.3[37,38]$. En la figura 4 se observa que los ítems 2 y 8 no cumplen con los criterios establecidos. El ítem 2 al presentar un índice de discriminación negativo es recomendable eliminarlo. El índice de discriminación promedio del test es 0.26 utilizando el método $50 \%-50 \%$ con todos los ítems y $0.35 \mathrm{si}$ se eliminan las preguntas 2 y 8 .

Coeficiente de punto biserial (r) es una medida de la consistencia de un ítem con todo el test. Refleja la correlación entre las calificaciones de los sujetos en un ítem con las calificaciones en todo el test. Tiene un rango entre $(-1,+1)$ [36-38]. Si un ítem es correlacionado positivamente con toda la prueba, significa que los sujetos con altos puntajes totales son más probables a responder que los sujetos con bajos puntajes totales. Un valor negativo indica que los sujetos con bajos puntajes totales fueron los más propensos a responder un ítem en particular correcto y es una indicación de que tal ítem es probablemente defectuoso. El rango recomendado es $\geqslant 0.2$ [37]. En la tabla 6, se muestran los resultados de este índice para cada ítem del test. Se observa el 
Tabla 6: Coeficiente de Relación Biserial de los Ítems del Test

\begin{tabular}{|l|c|c|c|c|c|c|c|c|c|c|}
\hline No. Ítem & 1 & 2 & 3 & 4 & 5 & 6 & 7 & 8 & 9 & 10 \\
\hline $\mathbf{r}$ & 0,392 & 0,091 & 0,362 & 0,354 & 0,557 & 0,395 & 0,362 & 0,294 & 0,449 & 0,539 \\
\hline
\end{tabular}

ítem 2, al presentar un índice inferior y cercano al recomendado, es el ítem más conflictivo del test. El promedio del coeficiente de punto biserial es 0.379 que también cumple con el criterio recomendado [36-38].

Indice de Kurder Richarson da cuenta de la consistencia o confiabilidad de un test completo. Éste índice permite ajustar todo el test y mide el poder discriminatorio de toda la prueba. Significa que si un test es aplicado en dos momentos distintos a una misma población de sujetos, habrá una alta correlación entre los puntajes de las dos pruebas asumiendo que el desempeño de los sujetos es constante en el tiempo y que las condiciones son las mismas en cada caso. La confiabilidad de este índice cae en un rango de $[0,1]$. El valor sugerido es mayor a 0.7 [36-38]. El valor obtenido en este índice para el test es aproximadamente de 0.7 eliminando los ítems 2 y 8 . Esto nos sugiere la necesidad de incrementar el número de ítems por cada concepto tratado en cada una de estas dos preguntas o como se indicó en el caso anterior su eliminación.

El último estadístico que se ha considerado es el Delta de Ferguson. Este índice es una medida del poder discriminatorio de un test que investiga que tan ampliamente están distribuidas las calificaciones de un test en el rango posible. Permite distinguir entre los sujetos con mayor o menor conocimiento sobre una idea determinada. Un test que ofrece un buen poder de discriminación es mayor a 0.9 [36-38]. El test que se ha desarrollado tiene un índice aproximado de 0.9 sin los ítems 2 y 8 , en concordancia con los análisis anteriores. En términos generales el instrumento en su conjunto tiene un nivel de dificultad medio. Para incrementar su confiabilidad y poder discriminatorio es necesario eliminar o remplazar los ítems 2 y 8 , con lo cual tras futuras mejoras puede proveer información objetiva en las muestras donde se investigue o se use.

\section{Resultados}

La descripción del análisis descriptivo del test la iniciaremos danto una mirada general. En la tabla
7 se presenta la distribución porcentual de respuesta para cada ítem. En negrita señalamos el mejor distractor considerado, y en cursiva el mejor distractor seleccionado por los participantes. En términos generales el distractor seleccionado a priori de la pregunta 2, 3, 7 y 9, desempeña su función. Sólo las preguntas 1, 2 y 4 sugieren que algunos participantes son capaces de identificar la dirección, magnitud y sentido del empuje y su par en el fluido. Además identifican las magnitudes que intervienen o dan cuenta de esta fuerza.

Con relación a la variable edad, como representamos en la figura 5, los sujetos mayores de 31 años y cuya especialidad en su gran mayoría es doctorado o máster, sólo sobresalen en la elección correcta de los ítems 1, 5, 6,7 y 10, en cambio los estudiantes de bachillerato con edades entre los 15 y 22 años aciertan con su respuesta en los ítems 2,8 y 9 . Los sujetos mayores de 31 años tienen por especialidad ingeniería y ciencias naturales (física, química y biología) de nacionalidad Española, y en igual proporción son hombres y mujeres. Los sujetos entre 15 y 23 años, son de nacionalidad Colombiana estudiantes de bachillerato y mujeres, y debido a que no tienen especialidad concreta en su bachillerato se han clasificado en otros. A continuación presentamos algunas ideas intuitivas halladas en nuestra muestra de 168 sujetos de distinto nivel académico y edad.

Tabla 7: Distribución de respuestas test TPA

\begin{tabular}{|l|c|c|c|c|}
\hline & \multicolumn{4}{|c|}{ Respuestas } \\
\hline No. Ítem & $\mathbf{A}$ & $\mathbf{B}$ & $\mathbf{C}$ & $\mathbf{D}$ \\
\hline 1 & $\mathbf{8 , 3} \%$ & $52,4 \% *$ & $7,1 \%$ & $32,1 \%$ \\
\hline 2 & $53,6 \% *$ & $2,4 \%$ & $\mathbf{2 8 , 6} \%$ & $15,5 \%$ \\
\hline 3 & $3,6 \%$ & $\mathbf{4 8 , 8} \%$ & $33,3 \%^{*}$ & $14,3 \%$ \\
\hline 4 & $84,5 \% *$ & $11,9 \%$ & $1,2 \%$ & $\mathbf{2 , 4 \%}$ \\
\hline 5 & $14,3 \%$ & $\mathbf{1 3 , 1} \%$ & $38,1 \%$ & $34,5 \%^{*}$ \\
\hline 6 & $29,8 \%$ & $19,0 \%$ & $\mathbf{1 7 , 9 \%}$ & $33.3 \%^{*}$ \\
\hline 7 & $7,1 \%$ & $\mathbf{3 8 , 1 \%}$ & $21,4 \%$ & $33,3 \%^{*}$ \\
\hline 8 & $\mathbf{2 7 , 4 \%}$ & $36,9 \%$ & $27,4 \% *$ & $8,3 \%$ \\
\hline 9 & $11,9 \%$ & $23,8 \%$ & $\mathbf{2 8 , 6} \%$ & $35,7 \%$ \\
\hline 10 & $35,7 \% *$ & $\mathbf{2 5 , 0 \%}$ & $13,1 \%$ & $26,2 \%$ \\
\hline
\end{tabular}

Revista Brasileira de Ensino de Física, vol. 38, nº 4, e4401, 2016 


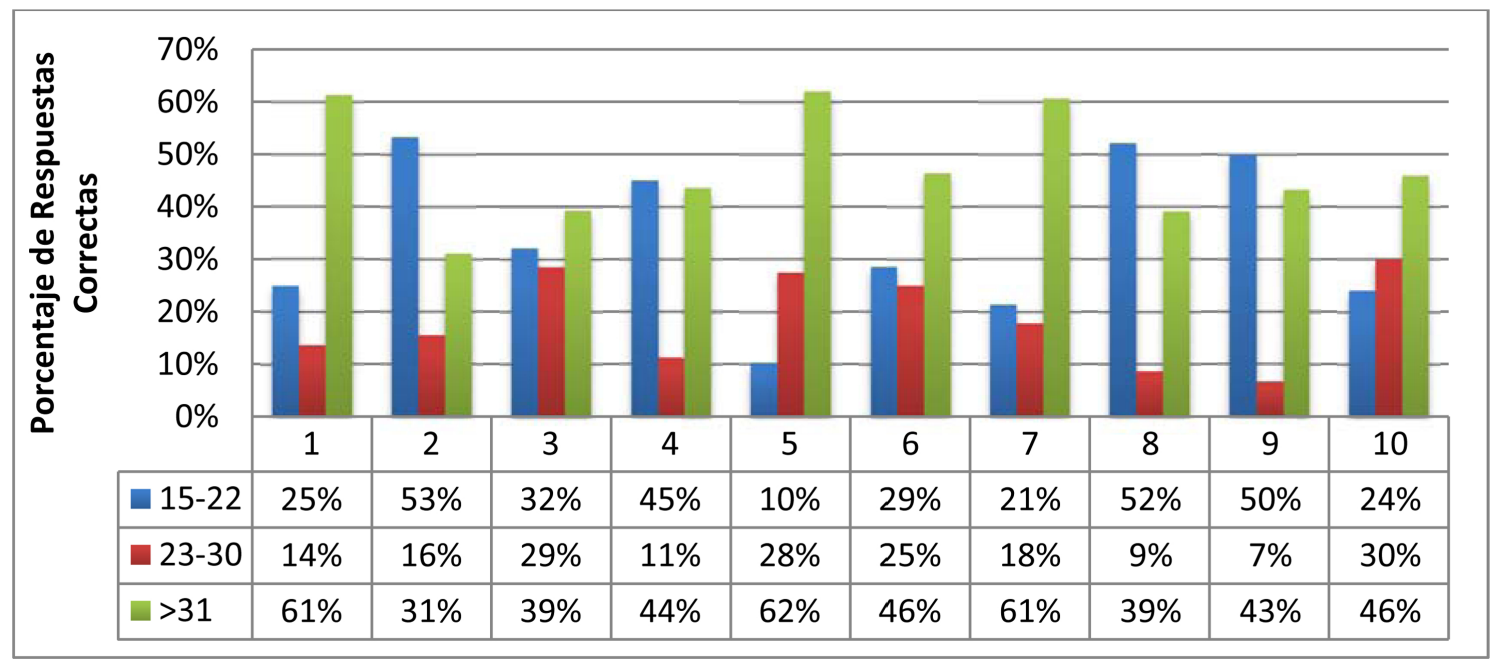

Figura 5: Distribución de respuestas correctas según la edad del TPA

\subsection{Ideas encontradas en el estudio sobre las dificultades de aprendizaje sobre el principio de Arquímedes}

Las ideas más recurrentes en la muestra analizada fueron:

1. Mayor volumen desplazado, mayor peso del líquido: El ítem 1 presenta una situación conocida, el incremento de la medida del peso de un líquido al introducir un sólido en un líquido. La intención era rastrear la justificación dada a esta situación haciendo uso de la tercera ley de Newton, y buscando que los participantes identificaran la fuerza de reacción a la fuerza de empuje como elemento participe de la respuesta. Un $32 \%$, como sugiere la respuesta $\mathrm{D}$ al ítem 1, señalan que el incremento de la medida del peso se debe a que el nivel de agua sube y a un aumento del volumen del agua, sin tener en cuenta que la cantidad de agua del sistema no se ha modificado. Esta idea es contrastada en el ítem 7 . La situación que se plante es la de una balanza de dos platillos donde, en uno de ellos se coloca un recipiente con agua hasta el borde y en el otro platillo un recipiente con agua y un trozo de madera. Los recipientes ubicados en los dos platillos tienen el mismo nivel de agua. En esta situación el volumen de agua deja de ser relevante, ya que es el mismo, pero en un $38 \%$ responde que el recipiente que contiene el sólido pesa más, con lo cual no se considera la idea peso del volumen desalojado y la fuerza de reacción sobre el líquido de igual magnitud que el empuje que experimenta el sólido (respuesta B del ítem 7 ), situación que acertadamente en un $53 \%$ fue contemplada en el ítem 1 . Un $21 \%$ sigue sin comprender las fuerzas que actúan sobre el sistema y señalan que el empuje es una fuerza que actúa en la misma dirección del peso al marcar la respuesta $\mathrm{C}$ del ítem 7 , respuesta que en el ítem 1 fue respaldada sólo en un $7 \%$.

2. Se recuerda la postulación del principio de Arquímedes sin reparar en un análisis de fuerzas: El ítem 2 relata una situación de un sólido sumergido sobre el que se coloca un sólido de menos peso. Se les solicita a los participantes recordar la definición del empuje y la dirección, sentido y magnitud de esta fuerza en una situación de equilibrio. Las situaciones 3 y 4 son variantes de la ya descrita. Los resultados nos sugieres que el $50 \%$ de los participantes de forma nemotécnica recuerdan la postulación del principio de Arquímedes sin reparar en un análisis de fuerzas, tal como señalamos en el apartado anterior. Además confunden la idea de presión y empuje, o no recuerdan lo que significa cada concepto tal como se ratifica en el ítem 10.

3. El empuje depende de la profundidad a la que se encuentren los cuerpos sumergidos: alrededor de un $13 \%$ consideran que el empuje depende de la posición del objeto sumergido, se evidencia en el ítem 5 respuesta $\mathrm{B}$ y en el ítem 6 respuesta C. Los encuestados indican la existencia de "grados de flotabilidad" según 
la posición del cuerpo sumergido, lo que nos lleva a suponer el uso de la idea de empuje como sinónimo de presión.

4. A mayor masa del cuerpo sumergido, mayor empuje. Como consecuencia de las respuestas del ítem 5, los participantes en un $38 \%$ consideran que el empuje se debe al peso del objeto sumergido, situación que nos lleva a pensar en la falta de reflexión sobre situaciones en las que el cuerpo está total o parcialmente sumergido y su relación con la flotación. Además se considera que el agua es un sostén del cuerpo sumergido y el empuje actúa similar a una fuerza normal como sugiere la respuesta $\mathrm{C}$ del ítem 5 .

5. Las interacciones sólo afectan a los sólidos: $\mathrm{El}$ ítem 8 conjuga distintos elementos, presión, principio de Pascal, principio de Arquímedes, es una de las preguntas que reportan mayor nivel de dificultad. La situación que se plantea es la de colocar un objeto en agua y sobre él verter aceite. El hecho contra-intuitivo "el frasco, al agregar el aceite, no se hunde más sino sube" no se presta a una explicación fácil de construir. Un $37 \%$ señalan la respuesta B la cual indica que el frasco permanecerá igual sin considerar el papel que el líquido no miscible ejerce sobre el otro, como si las interacciones fuesen sólo asunto de los sólidos. Un $28 \%$ al optar por la respuesta $\mathrm{C}$, piensan que el objeto se hunde más en agua debido a la fuerza del aceite sobre el agua sin contemplar la acción del agua sobre el aceite. En este caso los participantes identifican el empuje del agua y del aceite sobre el frasco a partir del líquido que desaloja. Sin embargo consideran que el peso del aceite ejerce un empuje extra adicional hacia abajo en el frasco reestructurando así su idea de empuje. Esta idea también puede verse en el ítem 9.

6. Los cuerpos pesan menos por estar sumergidos en un líquido: a través del ítem 9, que vincula la reflexión sobre el comportamiento (compresión y elongación) de un resorte, ubicado en una posición vertical y con un extremo atado al fondo de un recipiente sobre el que se vierte agua y sobre el que se coloca un sólido. A través de la pregunta vemos que los participantes en un $29 \%$ repiten de forma general la idea de que los cuerpos pesan menos por estar sumergidos en un líquido sin pensar en la existencia de la fuerza de empuje en dicha condición, aunque el peso de un cuerpo realmente es el mismo esté sumergido o no en un fluido, como sugiere la respuesta $\mathrm{C}$ al ítem.

\section{Conclusiones}

De acuerdo con los resultados obtenidos, el test que presentamos para determinar las dificultades de aprendizaje sobre el principio de Arquímedes presenta una fiabilidad y validez de contenido aceptables excluyendo los ítems 2 y 8 . Los resultados y las conclusiones que se derivan de este estudio hacen referencia únicamente a la muestra de sujetos que ha participado en él [39]. Consideramos que los resultados dependen del grado de recuerdo sobre el principio de Arquímedes y el diseño del test.

Llama la atención el bajo nivel de conocimiento conceptual sobre el principio de Arquímedes que han mostrado los participantes de este estudio y la poca diferenciación de las respuestas entre los estudiantes de bachillerato cuyas edades están comprendidas entre los 15 y 22 años y los titulados universitarios. Esto nos sugiere una revisión del patrón temático y las estrategias de enseñanza empleadas en la enseñanza de la hidrostática, reconociendo las potencialidades y limitaciones que sostienen los libros de texto al presentar el principio de Arquímedes. En concordancia con lo propuesto por Lima [4] consideramos que la fuerza de empuje puede definirse como "la fuerza neta que un fluido ejerce sobre la parte de la superficie de un cuerpo que esta efectivamente en contacto con el fluido" (p. 4), y en las explicaciones sobre el principio de Arquímedes deben debatirse los casos discrepantes donde los objetos sólidos sumergidos en los líquidos tocan las paredes de los recipientes

A través del test detectamos las siguientes ideas alternativas en concordancia con las reportadas en la literatura y las encontradas en los libros de texto analizados:

i) A mayor volumen, mayor peso.

ii) De forma nemotécnica los participantes intentan recordar la postulación del principio de Arquímedes sin reparar en un análisis de fuerzas, y en identificar los dos cuerpos que interactúan y que nos permiten hablar de la fuerza de empuje. 
iii) Los participantes no relacionan la presión con la altura, pero si al empuje con la altura. Además consideran que el empuje ejercido por un cuerpo es el mismo si se sumerge como un todo o se divide en distintas partes y todas sus partes se sumergen en el mismo recipiente.

iv) A mayor masa, mayor empuje.

v) No se considera la idea peso del volumen desalojado, y la fuerza de reacción sobre el líquido de igual magnitud que el empuje que experimenta el sólido. Es decir, la interacción sólo afecta los sólidos.

vi) Los cuerpos pesan menos por estar sumergidos en un líquido.

Finalmente consideramos que los ítems de este test pueden ser un instrumento de gran utilidad para la enseñanza-aprendizaje de la fuerza de empuje, tanto en contextos innovadores como en aquellos más tradicionales, para diferentes niveles de escolarización.

\section{Agradecimientos}

Los autores agradecen al Gobierno de Extremadura y al Fondo Social Europeo por la financiación recibida para la realización de esta investigación (Proyecto GR15009) y al Ministerio de Economía y Competitividad. Dirección General de Investigación (Proyecto: EDU2012-34140). L.V. Melo agradece a la Universidad de Extremadura la concesión de una beca predoctoral.

\section{Referencias}

[1] S. Çepni, y Ç. Şahin, Eurasian Journal of Physics and Chemistry Education 4, 97 (2012).

[2] L. Buteler y E. Colenu, Revista Electrónica de Enseñanza de las Ciencias 13, 137 (2014).

[3] R. Silva, J. Medina y E. López, Caderno Catarinense de Ensino de Física 1, 56 (1997).

[4] F.M.S. Lima, European Journal of Physics 33, 101 (2012).

[5] F.M. Barral, Enseñanza de las Ciencias 8, 244 (1990).

[6] D. Psillos y P. Kariotoglou, International Journal of Science Education 21, 17 (1999).

[7] V. Álvarez y M. Bernal, Alambique 25, 55 (2000).

[8] P.R.L. Heron, M.E. Loverude, P.S. Shaffer y L.C. McDermott, American Journal of Physics 71, 1188 (2003).

[9] J.M. Campanario, Enseñanza de las Ciencias 21, 161 (2003).
[10] M.E. Loverude, C.H. Kautz y P.R.L. Heron, American Journal of Physics 71, 1178 (2003).

[11] C. Maturano, S. Aguilar, G. Núñez y R. Pereira, Latin American Journal of Physics Education 3, 380 (2009).

[12] C. Mazzitelli, C. Maturano, G. Núñez y R. Pereira, Revista Eureka Sobre Enseñanza y Divulgación de las Ciencias 3, 33 (2006).

[13] E. Alurralde y J. Salinas, http://www.feeye uncu.edu.ar/web/posjornadasinve/area3/ Cienciasnaturalesysudidactica/060, consultada en Diciembre de 2014.

[14] A.L. Echegaray, M. Martínez y S. Stipcich, Experiências em Ensino de Ciências 1, 9 (2006).

[15] A. García-Carmona, Enseñanza de las Ciencias 27, 273 (2009).

[16] A. Madrigal y J. Slisko, Latin American Journal of Physics Education 4, 408 (2010).

[17] A. Blanco en: Competencias en el Conocimiento e Interacción con el Mundo Física: La Comprensión del Entorno Próximo, editado por A. Pro de Bueno (Ed. Ministerio de Educación, España, 2010), p. 137162.

[18] A.H. Clavijo y R. Paris, Revista Colombiana de Física 38, 682 (2006).

[19] M.I. Suero, A.L. Pérez, P.J. Pardo, M. Montanero y J. Gil, Aula Magna 29, 26 (2003).

[20] J. Radovanovic y J. Slisko, Physics Teacher 48, 428 (2012)

[21] F. Flores, L. Gallegos, H. Covarrubias, E. Vega, M. Rosas, B. García, M.A. Álvarez, S. de León, P. Lizárraga y A. Meza, en: The Proceedings of the Third International Seminar on Misconceptions and Educational Strategies in Science and Mathematics (New York, 1993), p. 3-15.

[22] P. Kariotogoy, P. Koumaras y D. Psillos, Physics Education 28, 164 (1993).

[23] L. Alcocer, R. Carrión, J.J. Alonso y J. Campanario, Revista Electrónica de Enseñanza de las Ciencias 3, 98 (2004).

[24] C. Bañas, V. Mellado y C. Ruíz, Caderno Brasileño de Ensino de Física 21, 296 (2004).

[25] J.A. Fidalgo y M.R. Fernández, 4 ESO Física y Química (Everest, España, 2003), p. 46-65.

[26] G. Ontañón, E. Ontañon, J.A. Fernández-Cano y F. Arce, 4 ESO Física y Química (Bruno, Madrid, 2007), p. 138-159.

[27] A. Fontanet y M.J. Martínez, 4 ESO Física y Química (Vicens Vives, España, 2008), p. 92-113.

[28] P. Hewit, Física Conceptual (Pearson Educación, México, 2007), 10 a ed., p. 248-267.

[29] M. Bautista y F.L. Salazar, Hipertexto Física 1 (Editorial Santillana, Bogotá, 2011), p. 214-224.

[30] D. Giancoli, Física para Ciencias e Ingeniería, Volumen I (Pearson Educación, México, 2008), 4⿳⺈ ed., p. 255-285. 
[31] P.E. Tippens, Física Conceptos y Aplicaciones (McGraw Hill, México, 2011), $7^{\text {a }}$ ed., p. 301-328.

[32] J. Slisko, Revista Eureka sobre Enseñanza y Divulgación de las Ciencias 2, 364 (2005).

[33] J. Slisko, Revista Eureka sobre Enseñanza y Divulgación de las Ciencias 3, 51 (2006).

[34] C. Maturano, C. Mazzitelli, G. Núñez y R. Pereira, Revista Electrónica de Enseñanza de las Ciencias 4, 2 (2005).

[35] FMS Lima, G.M. Venceslau e GT Brasil, Revista Brasileira de Ensino de Física 36, 2309 (2014).

[36] L.H. Barbosa, Revista Educación en Ingeniería 8, 24 (2013).

[37] L. Ding, R. Chabay, B. Sherwood y R. Beichner, Phys. Rev. ST Phys. Educ. Res. 2, 0101051 (2006).

[38] P. Barniol y G. Zabala, Phys. Rev. ST Phys. Educ. Res. 10, 010121 (2014).

[39] M. Martínez-Grau, J.J. Solaz-Portolés y V. Sanjosé, Quimica Nova 37, 740 (2014).

[40] http://www.scienceinschool.org/print/3007, consultada en Diciembre de 2014.

[41] M. Oliver-Hoyo, F. Alconchel y G. Pinto, Revista Española de Física 26, 45 (2012).

[42] F. Fontana y R. Di Capua, European Journal of Physics 26, 1017 (2005).

[43] L. Viennot, Lat. American Journal of Physics Edu 2, 21 (2008). 


\section{Anexo 1}

\section{¡EUREKA!, ¡EUREKA!}

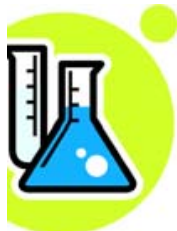

El cuestionario que te presentamos a continuación y que agradecemos que nos respondas, está elaborado con la finalidad de analizar algunas ideas frecuentes en el campo de la hidrostática. Te recordamos que las respuestas son totalmente anónimas, por lo que te agradecemos que seas sincero/a. Todas las preguntas de este cuestionario, van seguidas por cuatro respuestas posibles. Señala con una $\mathbf{X}$ la respuesta que consideres correcta. En caso de que ninguna de las opciones se ajuste a lo que tú consideras, plantea tu propia solución. También marca con una $\mathbf{X}$, el grado de seguridad de tu respuesta, para ello hemos dispuesto cuatro opciones: totalmente segura/o, segura/o, indecisa/o, y al azar

\section{DATOS PERSONALES Y ACADÉMICOS}

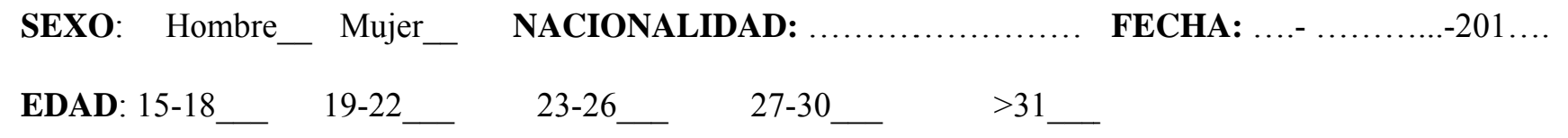

NIVEL ACADÉMICO: Secundaria___ Bachillerato__ Técnico/Tecnólogo Diplomado/Ingeniero/Licenciado/Grado___ Máster/Doctorado Otro:..............................

Especialidad de tus Estudios:
Ciencias de la Salud
CC Sociales y Jurídicas Ciencias de la Naturaleza Ingeniería

Otras

1. Se coloca un vaso de agua sobre una balanza y se anota la medida. A continuación se introduce un dedo en el vaso sumergiéndolo en el agua sin tocar las paredes como se muestra en la fotografía 1, la lectura de la balanza aumenta (Pregunta adaptada de: www.scienceinschool.org [40]):

A) debido al peso del dedo

B) debido a la fuerza de reacción al empuje que el agua ejerce sobre el dedo.

C) debido al empuje que ejerce el agua sobre el dedo

D) debido a que sube el nivel del agua, a más volumen de agua más peso.
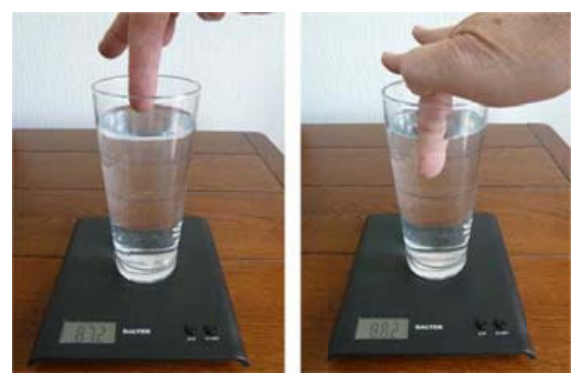

Fotografía 1, Fuente [40]

OTRA:

\section{Indica si la respuesta elegida ha sido de forma}

Totalmente Segura/o

Segura/o

Indecisa/o

Al azar

2. Colocamos una barca sobre un recipiente con agua y a continuación colocamos una piedra en la barca como muestra la figura 1 . Se puede afirmar que:

A) el empuje que ejerce el agua es igual al peso de la barca más el peso de la piedra.

B) el empuje que ejerce el agua es igual al peso de la barca menos el peso de la piedra.

C) el empuje que ejerce el agua es igual al peso del volumen desalojado por la barca

D) el empuje que ejerce el agua es igual al volumen de la barca más el volumen de la piedra

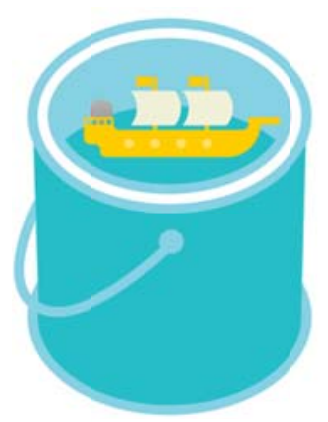

Figura 1 
Otra:

\section{Indica si la respuesta elegida ha sido de forma}

Totalmente Segura/o

Segura/o

Indecisa/o

Al azar

3. Sobre un recipiente de plástico colocamos dos huevos y se colocan en la superficie de un vaso de agua con sal (fotografía 2). Si sacamos los huevos del recipiente de plástico éstos se hundirán (fotografía 3); podemos decir que el nivel del agua (Pregunta adaptada de Oliver-Hoyo et al. [41]):
A) Permanece igual
B) Sube
C) Baja
D) Ninguna respuesta es correcta
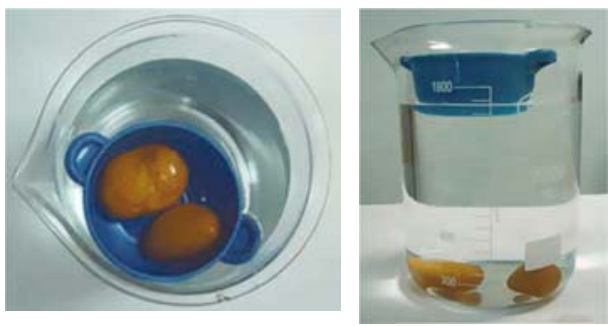

Fotografía 2 Fuente [41]

Otra:

\section{Indica si la respuesta elegida ha sido de forma}

Totalmente Segura/o

Segura/o

Indecisa/o

Al azar

4. Dos bloques metálicos exactamente iguales (A y B) se sumergen en agua como se muestra en la figura 2. Podemos afirmar que (Pregunta adaptada de Suero et al. [19]):

A) Ambos bloques desplazan igual volumen de agua puesto que tienen la misma densidad

B) El bloque A desplaza un volumen mayor de agua puesto que la presión es mayor en su base

C) El bloque B desplaza un volumen mayor de agua puesto que la presión es

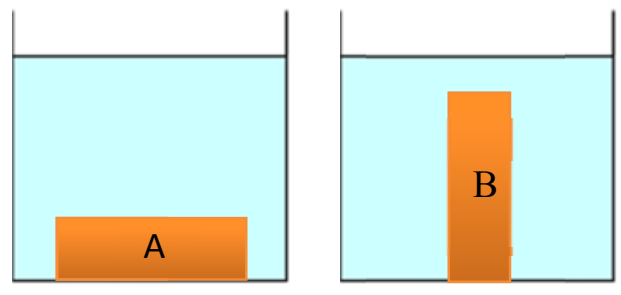

Figura 2 menor en su base

D) El bloque A desplaza un mayor volumen de agua, puesto que ocupa más superficie en el fondo.

Otra:

Indica si la respuesta elegida ha sido de forma

Totalmente Segura/o

Segura/o

Indecisa/o

Al azar

5. Tres cubos A, B y C de igual volumen, se sumergen en alcohol como muestra la figura 3. El cubo A y $\mathrm{C}$ tienen igual masa y mayor que $\mathrm{B}$, podemos decir que (Pregunta adaptada de Loverude et al. [10]):
A) B experimento un empuje menor por tener menos masa que $\mathrm{A}$ y $\mathrm{C}$
B) A y $\mathrm{C}$ experimentan el mismo empuje debido a que se encuentran al mismo nivel
C) A y $\mathrm{C}$ experimental el mismo empuje por tener el mismo peso
D) A, B y C experimental el mismo empuje

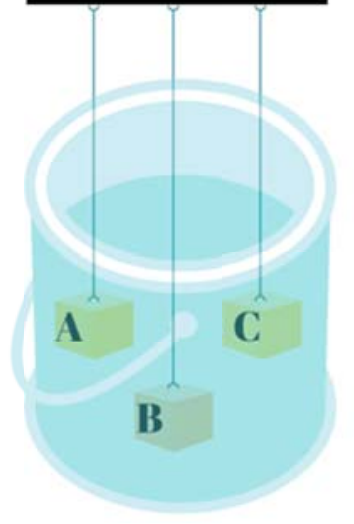

Figura 3 
Otra:

\section{Indica si la respuesta elegida ha sido de forma}

Totalmente Segura/o

Segura/o

Indecisa/o

Al azar

6. Dos objetos A y B exactamente iguales como se muestra en la figura 4, se colocan en dos vasos que contienen líquidos de densidades diferentes, en ambas situaciones los cuerpos flotan. Si la cantidad de líquido en cada vaso es de $50 \mathrm{ml}$, podemos afirmar que (Pregunta adaptada de Loverude et al. [10]):

A) El empuje que experimenta el cuerpo sumergido en el líquido de mayor densidad es mayor

B) El empuje que experimentan los cuerpos A y B es el mismo

C) El cuerpo inmerso en el líquido de menor densidad está más sumergido por tanto el empuje es mayor

D) El nivel de líquido en los dos vasos después de introducir los cuerpos es el mismo, sólo que el cuerpo que se encuentra en el líquido más denso está menos sumergido

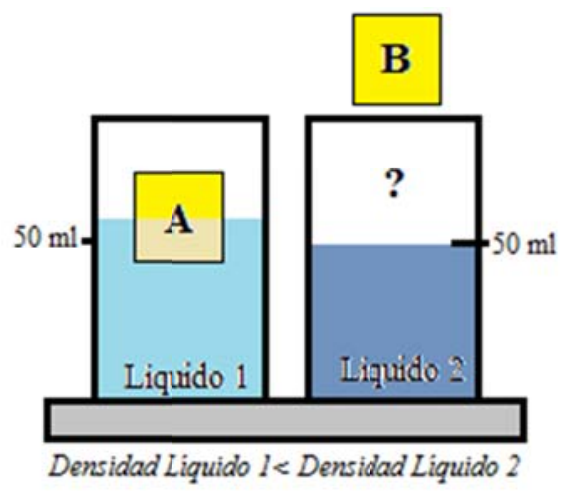

Figura 4

Otra:

Indica si la respuesta elegida ha sido de forma

Totalmente Segura/o
Segura/o

Indecisa/o
Al azar

7. En uno de los platillos de una balanza hay un cubo lleno totalmente de agua (A). En el otro, un cubo exactamente igual (B), también lleno totalmente hasta los bordes, pero en él flota un trozo de madera (figura 5) ¿Qué cubo pesa más? (Pregunta adaptada de Fontana y Di Capua [42])

A) El cubo A pesa más porque contiene más agua que el cubo $B$

B) El cubo $\mathrm{B}$ pesa más porque además del peso del agua se tiene el de madera

C) El cubo B pesa más debido al empuje que ejerce el agua sobre la madera

D) Los dos cubos pesan lo mismo debido a que el nivel del agua es el mismo

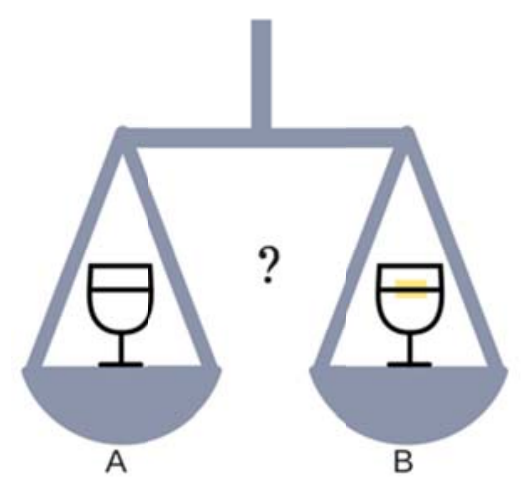

Figura 5

Otra:

Indica si la respuesta elegida ha sido de forma

Totalmente Segura/o

Segura/o

Indecisa/o

Al azar 
8. Consideremos un objeto que flota en el agua pero se hunde en el aceite (fotografía 4). Si se vierte aceite lentamente sobre el vaso de agua hasta que se cubra totalmente el objeto, cuando se alcance el equilibrio (Pregunta adaptada Buteler y Colenu [2], Radovanovic y Slisko [21], Viennot [43]):
A) El objeto se hundirá más en el agua
B) El objeto permanecerá en la misma altura respecto al nivel del agua
C) El objeto subirá con respecto al nivel del agua
D) Ninguna respuesta es correcta.

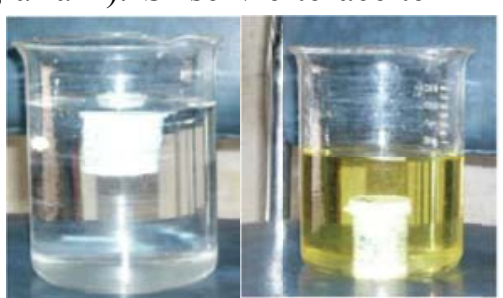

Fotografía 4, Fuente [2]

Otra:

Indica si la respuesta elegida ha sido de forma

Totalmente Segura/o
Indecisa/o

Al azar

9. Un resorte está unido a la parte inferior de un gran recipiente vacío, con el eje del resorte orientado verticalmente. Un bloque de $2 \mathrm{~kg}$ se fija a la parte superior del resorte y lo comprime una distancia x como se muestra en la figura 6. A continuación el recipiente se llena de agua hasta el borde. Se puede afirmar que:

A) La elongación del resorte dependerá de la diferencia de densidad entre el agua y el bloque

B) El resorte se comprimirá una longitud mayor que $\mathrm{x}$ debido a la masa de agua sobre el bloque

C) El resorte se comprimirá una distancia menor que $\mathrm{x}$ debido a que todos objetos dentro del agua pesan menos que en el aire.

D) El resorte se comprimirá una distancia menor que $\mathrm{x}$ debido al empuje que realiza el agua sobre el bloque

Otra:

\section{Indica si la respuesta elegida ha sido de forma}

Totalmente Segura/o

Segura/o

Indecisa/o

Al azar

10. Los recipientes que se muestran en la figura 7 contienen agua hasta el mismo nivel y tienen igual área en la base. Se puede afirmar qué:

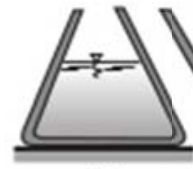

(1)

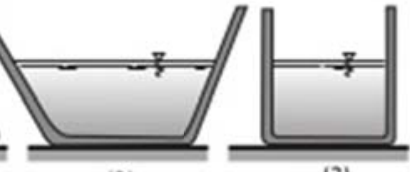

(2)

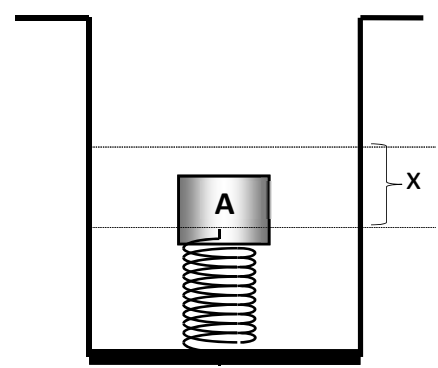

Figura 6

Figura 7

A) W2 $>\mathrm{W} 3>\mathrm{W} 1$, donde $\mathrm{W}$ representa el peso del recipiente con agua

B) $\mathrm{P} 2>\mathrm{P} 3>\mathrm{P} 1$, donde $\mathrm{P}$ represente la presión en el fondo del recipiente

C) $\mathrm{E} 2>\mathrm{E} 3>\mathrm{E} 1$, donde E representa el empuje en el fondo del recipiente

D) $\mathrm{E} 1=\mathrm{P} 1$ 
Otra:.

Indica si la respuesta elegida ha sido de forma

Totalmente Segura/o

Segura/o

Indecisa/o

Al azar

¡Muchas Gracias! 